\title{
Einwirkung von Stosswellen auf tierische Zellkulturen Licht- und elektronenmikroskopische Untersuchungen
}

Th.Bräuner, F.Brūmmer, D.F.Hülser

Abteilung Biophysik, Biologisches Institut der Universităt Stuttgart

Zur Charakterisierung biologischer Eigenschaften von Stoßwellen setzten wir Einzelzellsuspensionen der Maus-Leukämie-Zellinie L1210 sowie kugelförmig wachsende Zellaggregate, sogenannte Multizell-Sphäroide, verschiedener Tumorzellinien ein. Die Stoßwellen wurden durch Unterwasser-Funkenentladung $(18 \mathrm{kV}, 80 \mathrm{nF}$, $1 \mathrm{~Hz}$ ) in einem Experimental-Lithotripter (Typ XL 1) der Firma Dornier Medizintechnik erzeugt. L1210-Zellsuspensionen, die in PolyethylenPipetten bei $37^{\circ} \mathrm{C}$ in teilentgastem Wasser mit 500 Stoßwellen behandelt wurden, zeigten in der lichtmikroskopischen Histologie unregelmäßige Zellformen, Änderungen des Färbeverhaltens, Hohlräume im Zytoplasma sowie Zellfragmente unterschiedlicher Größe. Im Elektronenmikroskop waren Auftreibungen des endoplasmatischen Retikulums, Schädigungen der Mitochondrien, große Hohlräume im Zytoplasma, Ablösungen des Zytoplasmas vom Zellkern sowie zahlreiche permeabilisierte Zellen zu erkennen.

In weiteren Experimenten wurden MultizellSphäroide eingesetzt, die durch ihr räumliches Wachstum den Verhältnissen eines intakten Gewebes näherkommen als Einzelzellsuspensionen. Wurden die sedimentierten Multizell-Sphäroide in den zweiten Brennpunkt des Halbellipsoids positioniert, war mit jeder Stoßwelle eine heftige Aufwirbelung der Multizell-Sphäroide zu beobachten. Mit steigender Dosis trübte sich die Suspension durch abgeschlagene Zellen. Zellverluste in der äußeren Zellschicht konnten in histologischen Schnitten bereits nach Behandlung mit 100 Sto $\beta$ wellen nachgewiesen werden, höhere Dosen (250750 Stoßwellen) fuhrten zur Schädigung tieferer Zellschichten, zu Verlusten größerer Zellgruppen im Randbereich des Sphäroids bis hin zur völligen Fragmentierung. Unter gleichen Bedingungen traten bei Multizell-Sphäroiden aus epitheloiden HeLa-Zellen (Gebärmutterhalskarzinom-Zellen des Menschen) stärkere Schäden auf als bei MultizellSphäroiden aus fibroblastoiden EMT6/Ro-Zellen (Brusttumor-Zellen der Maus). In elektronenmikroskopischen Dünschnitten waren besonders in den Randschichten der Multizell-Sphäroide ähnliche Zellschäden $\mathrm{zu}$ beobachten wie sie für Einzelzellsuspensionen der Linie L1210 beschrieben wurden.

Wurden die Multizell-Sphäroide in Agar oder Gelatine immobilisiert, war selbst nach Behandlung mit 500 bis 750 Stoßwellen keine Schädigung in licht- und elektronenmikroskopischen Dünnschnitten zu erkennen.

Diese vergleichenden Experimente lassen den Schlu $\beta$ zu, daß sekundäre Effekte der Stoßwelle, wie Beschleunigungs- und Scherkräfte, für die Schädigung von Einzelzellen und Multizell-Sphäroiden in Suspension verantwortlich sind. Durch die Immobilisierung der Zellkulturen in Agar oder Gelatine können dagegen Beschleunigungskräfte und die dadurch bedingten Sekundäreffekte ausgeschlossen werden. Damit wird eine stärkere Annäherung der experimentellen in-vitro-Situation an die Verhältnisse im lebenden Organismus möglich. 